Volume 9. No.12, December 2021

International Journal of Emerging Trends in Engineering Research

Available Online at http://www.warse.org/IJETER/static/pdf/file/ijeter069122021.pdf

https://doi.org/10.30534/ijeter/2021/069122021

\title{
Microstructure and Mechanical properties development of ZA27 alloy through heat treatment
}

\author{
Elsayed K. Maree*1 \\ 1. Faculty of Engineering, Mining and Metallurgy \& Petroleum Department, Al-Azhar University, P.O. Box: \\ 5043, Qena, Egypt \\ *Corresponding author: sayedplc1@yahoo.com, ORCID ID: 0000-0002-6716-7716, phone: +20 1129487720
}

Received Date : November 06, 2021 Accepted Date : November 29, 2021 Published Date : December 07, 2021

\begin{abstract}
In this work, ZA-27 alloy was fabricated and solid solution treatment at 120,240 and $360^{\circ} \mathrm{C}$ for $1 \mathrm{hr}$., microstructure and physical properties of alloy were studied by X-ray diffraction, scanning electron microscopy. Results observed that the microstructure of ZA-27 alloy manufactured (as-cast) was composed of $\alpha, \beta, \eta$ and $\varepsilon$ phases, then decomposed to $\beta$ phase at $360 \mathrm{oC}$. The heat treatment of ZA-27 alloys influenced on microstructure, decreasing of strength and hardness, but also causes increasing of elongation. The wear rates of changes increase with increasing solid solution treatment.
\end{abstract}

Key words : ZA-27 alloy fabrication; heat treatment; solid solution; microstructure; physical and mechanical properties, Wear Resistance, worn surface

\section{INTRODUCTION}

A series of zinc based alloys were first developed as the ZAMAK alloys in 1970s, North America[1]. Aluminum content was selected as about $8 \%, 12,22$ and $27 \%$ (weight fraction) and the content of copper up to $3 \%$ (mass fraction). They named after its aluminum content as ZA8, ZA12, ZA22 and ZA27, respectively [2-8]. A phase diagram of $\mathrm{Zn}-\mathrm{Al}$ alloys as shown in Figure 1, the solidification and microstructure evolution of ZA27 alloy is fairly complex due to the existence of uniform grain, eutectic and segregation and other reactions [9].

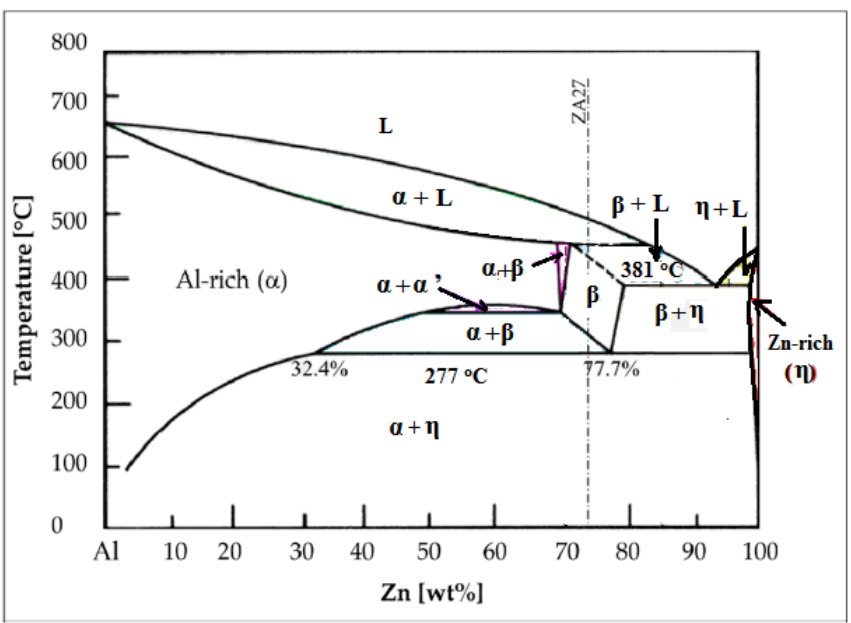

Figure 1: Zinc-Al phase diagram [9].

ZA-27 alloy used widely as substitute of cast malleable iron and brass for making wear resistance parts of engine. It is used extensively as bearing materials due to its excellent castability, damping capacity highly, good fluidity, low coefficient of friction, wear resistance highly in both lubrication and dry conditions and simultaneously reduces cost of production [10-14]. The ZA-27 alloys have highly strength, hardness, and wear resistance, as well as other favorable physical properties. The properties make its an attractive alternative to aluminium, brass, bronze, or iron for the designer of structures and machine parts that can be cast. Therefore, it has obtained more and more applications in industries. Finally, too interest has been attracted to investigate the damping capacities of ZA-27 alloy, since the alloy has excellent mechanical properties and high capacities of damping [15]. Various methods and techniques were used to substantially improve the damping capacities of zinc-aluminum alloys without lowering significantly the mechanical properties of materials. Studies show that the damping capacities of $\mathrm{Zn}-\mathrm{Al}$ alloys could be improved by proper heat treatment. The hardness, ductility, strength and 
dimensional shrinkage of the supersaturated ZA-27 alloy during the aging were studied extensively, but the damping capacity variation during the process is less studied [16]. In the real casting conditions the ZA-27 alloy has the typical dendritic structure, which size depends on the applied casting structure. Namely the cooling speed imposes a strong influence on the structure fineness, during the cooling in the mold [17-19]. The dendritic structure consequences are manifested, primarily, in the lower ductility of casted alloy, as well as in relatively high in homogeneity of the mechanical properties [20]. Melt thermal-rate treatment technique a one category of heat treatment by which the melt is first superheated to a certain higher temperature, usually more 250 oC above its liquidus, and held at this temperature for some time and then cooled quickly to a poring temperature before pouring [21]. With the temperature increase, the non-uniform melt transforms into uniform melt, and then through high rate cooling, the fine and uniform microstructures of the high-temperature melt are retained. This technique maybe improve the microstructure and mechanical properties of alloys [22]

An objective of this study, focusing on development of hypereutectic alloys using gravity casting technique., manufacturing ZA-27 alloys, and also applied the physical characterize and mechanical properties such as: microstructures, densities, ultimate tensile strength, percent elongation, hardness, impact strength of ZA27 alloys in both as-cast and heat treated

\section{EXPERMENTS AND PROCEDURE}

\subsection{Chemical Composition of ZA-27 Alloy}

In this work, ZA-27 alloy manufactured from material with higher purity metals. The chemical composition of this alloy shown in Table:1. As chemical compositions of ASTM B86 standard

Table 1: Chemical Compositions of ZA-27

\begin{tabular}{|l|l|l|l|l|}
\hline $\mathbf{Z n}$ & $\mathbf{M g}$ & $\mathbf{C u}$ & $\mathbf{A l}$ & Elements \\
\hline Balance & $0.01-$ & $1.0-2.5$ & $25-28$ & $\begin{array}{l}\text { Percentag } \\
\text { e }\end{array}$ \\
& 0.02 & & & \multicolumn{2}{|c}{} \\
\hline
\end{tabular}

\subsection{Material}

The Aluminum used in ZA-27 alloy was from Egyptaluminum Co., with purity 999 and Magnesium was from Alpha Chemicals, copper metal used in produce zinc aluminum alloy ZA-27 was purity 99.9 and characterized by $\mathrm{XRD}$ and zinc metal balance used in ZA-27 preparation was 99.99, from from Boliden's Kokkola, Finland.

\subsection{Produce of ZA-27 alloy by stir-casting}

The ZA-27 alloy was $(27 \% \mathrm{Al}, 2 \% \mathrm{Cu}, 0.02 \% \mathrm{Mg}$ and balance $\mathrm{Zn}$ ), processed by the liquid metallurgy route (stir cast). The Alloy was melted in a graphite crucible in an electric resistance furnace as figure 2. The ZA-27 alloy was produced at $600{ }^{\circ} \mathrm{C}$ by first melt of aluminum and copper added magnesium finally balance of zinc, and the alloy cast into a steel mold with dimension 120 x 40 x $10 \mathrm{~mm} 3$, samples cooling in air and other quenched in cold water .

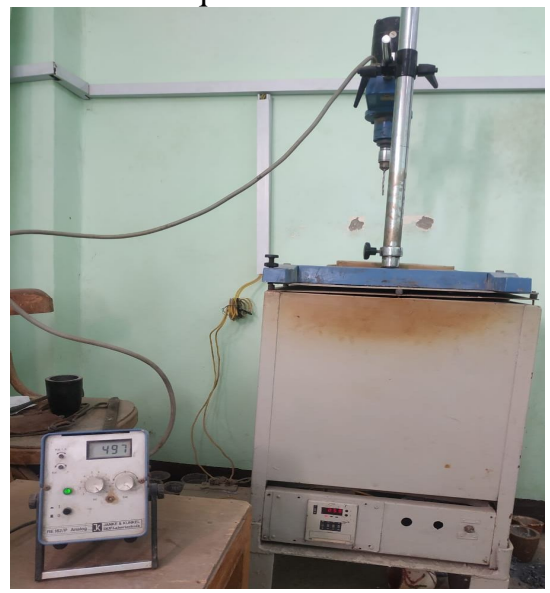

Figure 2: Electric resistance furnace

Quenched samples were exposed to heat treatment at 120, 240 and $360^{\circ} \mathrm{C}$ about $1 \mathrm{hr}$. The samples were grinded and polished for a smooth surface finish using different grits of silicon carbide papers. Nitric cid (5\% conc.) used as etching. Both of as-cast and heat-treated samples were investigated by SEM equipped with Gensis70 energy dispersive X-ray spectrometer (EDS). The microstructure and phases to all samples were investigated by using X-ray diffractometer (XRD) philips D500 type operated at $45 \mathrm{~mA}$ and $40 \mathrm{kV}$. Characteristic XRD patterns were obtained within a diffraction angle (20). Densities of ZA27 were investigated by pycnometer used inert gas(nitrogen). Macro-hardness of both the as-cast and heat-treated samples were measured using Vickers hardness tester at room temperature and average at least 5 random indentations under $500 \mathrm{gr}$ for $15 \mathrm{~s}$. The tensile strength and micro hardness both of the ZA27 as cast and heat treatment samples were applied at room temperature. Compression strength of samples were measured using uniaxial $350 \mathrm{KN}$ capacity.

\section{RESULTS AND DISCUSSION}

\subsection{Microstructure characteristics}

In microstructure of ZA-27 alloy, first, $\alpha$ primary phase was solidified to build dendrites foundation, bordered by the $\beta$ phase. The $\eta$ phase and $\varepsilon$ phase solidified neatly in inter dendrite area. Microstructure indicated dendrite multi-phase structures as shown in figure 3-A), after heat treatment at 120 ${ }^{\circ} \mathrm{C}$ for $1 \mathrm{hr}$. a microstructures of ZA-27 alloy its observe the primary $\alpha$-Al dendrites decomposed into $\beta$ phases and but with out change rather, primary $\alpha$-Al dendrites, in spite of the increase of $\alpha-\mathrm{Al}$ phase volume fraction, as shown in the low magnitude images of figure 3-B). ZA-27 solution treatment at $240{ }^{\circ} \mathrm{C}$ led to the reduction of $\alpha$ - $\mathrm{Al}$ dendrites and $\eta$ phases in to $\beta$ phase as shown in figure 3-C)., the ability of diffusion of elements is improved at higher temperature. When ZA-27 solid solution treatment at $360{ }^{\circ} \mathrm{C}$ for $1 \mathrm{hr}$., the matrix was saturated with $\beta$ phase, where the Al-rich $\alpha$ phase appeared as a dark particles. This is because the discontinuous 
precipitation was developed along the grain boundaries in the $\beta$ phase as shown in figure 3-D),

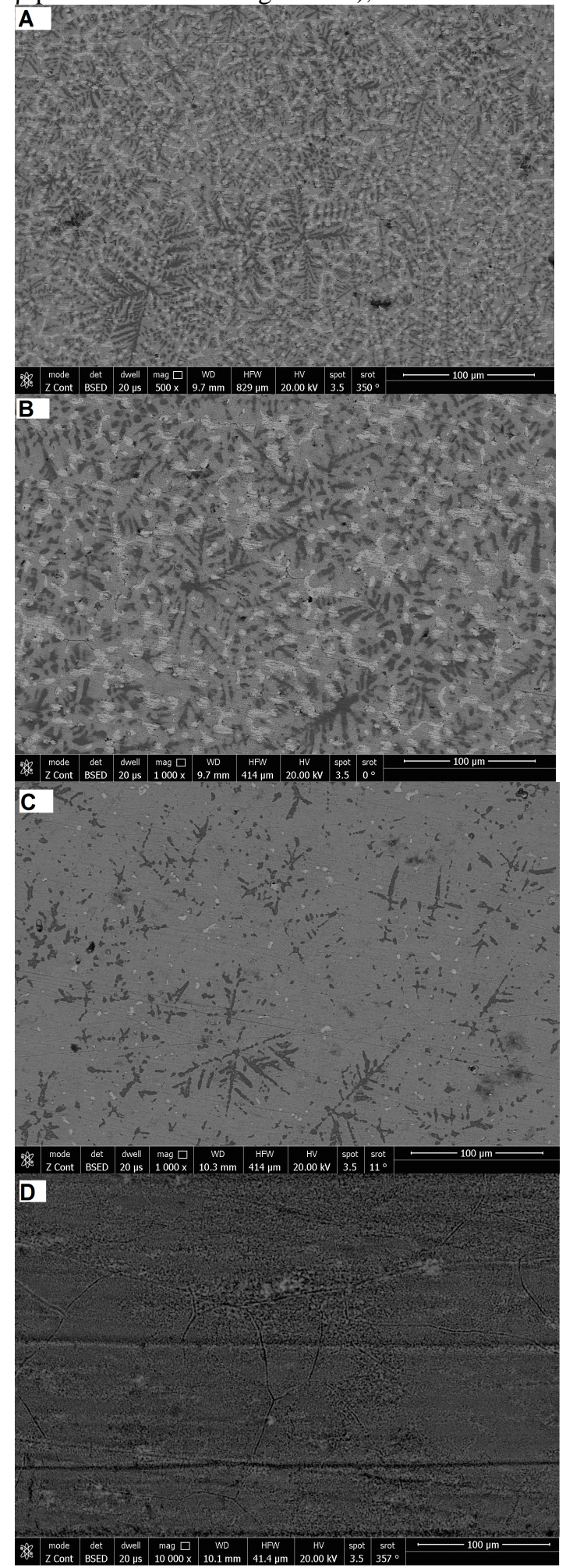

Figure 3: SEM images of ZA-27 alloy heat treatment for $1 \mathrm{hr}$; A) at $\left.0{ }^{\circ} \mathrm{C}, \mathrm{B}\right)$ at $120^{\circ} \mathrm{C}$, b) at $240{ }^{\circ} \mathrm{C}$ and D) at $360{ }^{\circ} \mathrm{C}$

The average composition of each phase was determined using EADS and is listed in figure 4, A) $\alpha$ phase, B) $\eta$ phase, C) $\varepsilon$ phase, D) $\beta$ phase
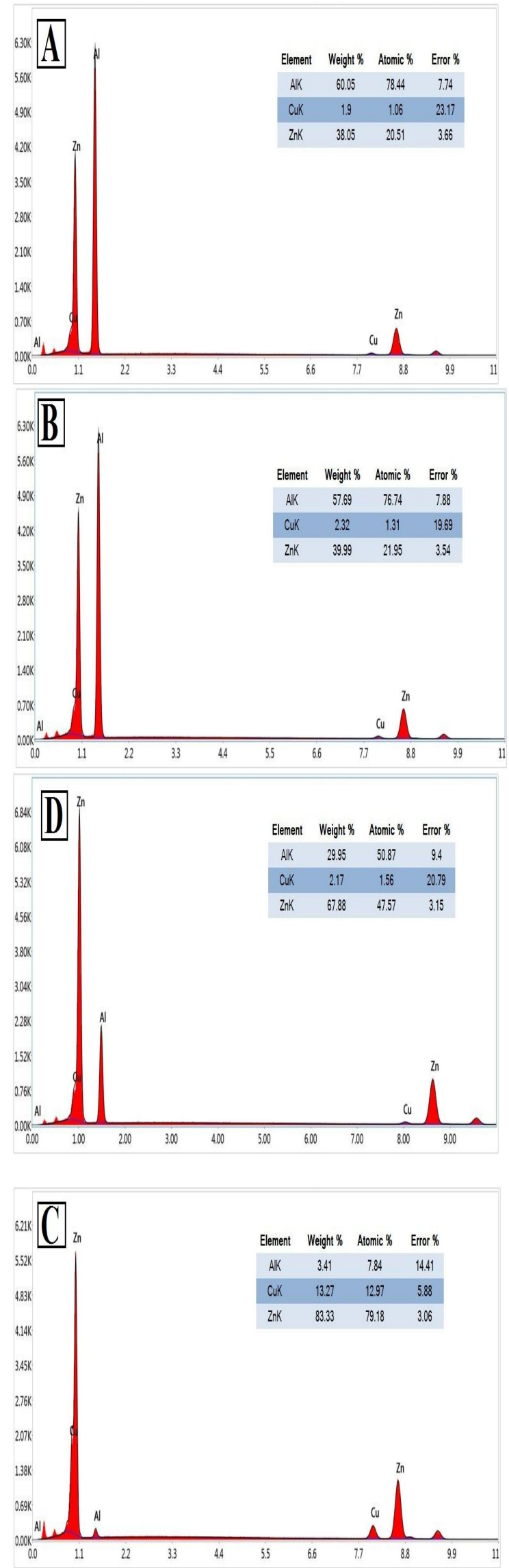

Figure 4: EADS of ZA-27 alloy with average composition of phases 


\subsection{XRD Characteristics}

According to the XRD investigation, $\alpha, \eta, \beta$ and $\varepsilon$ phases appear in ZA-27 alloy as-cast, where the diffraction peaks of the phases were characteristic separately indexed. The peaks (111) and (200) of $\alpha$ phase appeared at $2 \theta=38.444^{\circ}$ (d-spacing $2.33970 \mathrm{~nm}$ ) and $44.688 \quad 44.7^{\circ}$ (d-spacing 2.02620). The peaks (0002) and (1010) of the $\eta$ phase were at $2 \theta=36.291^{\circ}$ (d-spacing $2.47340 \mathrm{~nm}$ ) and $38.997^{\circ}$ (d-spacing $2.30780 \mathrm{~nm})$, respectively. The peaks (10 $\overline{\mathrm{I}} 0)$ and (002) of $\varepsilon$ phase $(\mathrm{CuZn} 4)$ were at $2 \theta=37.8^{\circ}(\mathrm{d}$-pacing $0.2378 \mathrm{~nm})$ and $42.3^{\circ}$ ( $d$-spacing $\left.2.134 \mathrm{~nm}\right)$, respectively. The peak ( $\left.10 \overline{\mathrm{I}} 1\right)$ of both $\eta$ and $\varepsilon$ phases overlapped at $2 \theta=43.420^{\circ}$ ( $d$-spacing $2.08240 \mathrm{~nm}$ ). The XRD patterns of the ZA-27 alloy after heat treatment at 120, 240 and $360^{\circ} \mathrm{C}$ for $1 \mathrm{hr}$ are shown in Figure 11. It was observed that the diffraction intensity of phases $\alpha, \eta$ and $\varepsilon$ in solid solution treatment decrease in solution treatment with increase of temperature as shown in Figure 5

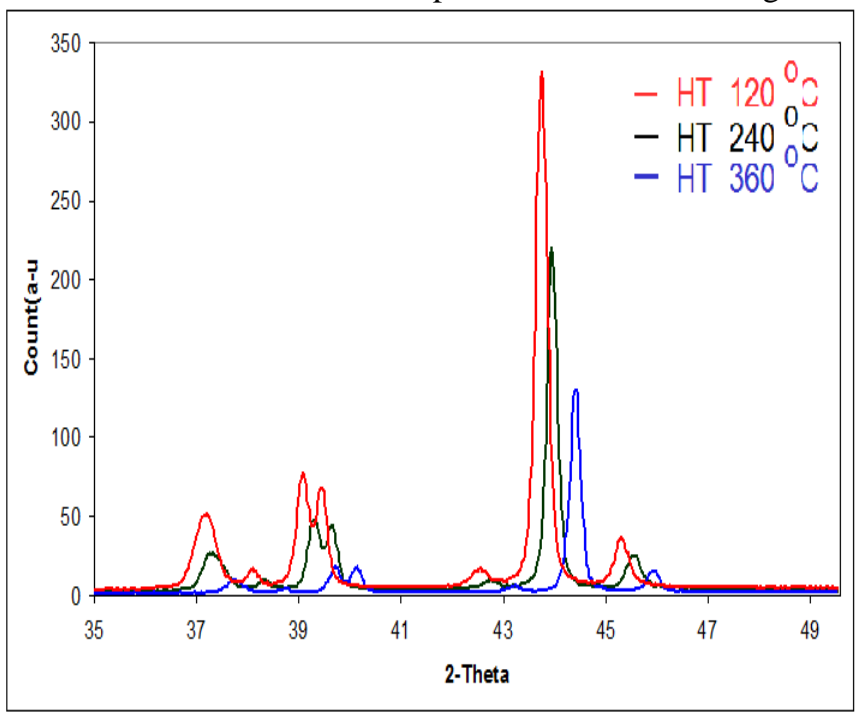

Figure 5: $\mathrm{XRD}$ patterns of ZA-27 alloy heat treatment at different temperature for $1 \mathrm{hr}$.

\subsection{Density}

ZA27 (as-cast and heat treatments) densities depend on microstructure; and microstructure was as complex function of casting and cooling and heat treatment process. Figure: 6, shown the theoretical and experimental variations in density. in cast and heat treatment samples densities differences may be due to change in dimensional during heat treatment, by change of meta stable phases to stable phase, which retained by non equilibrium solidification

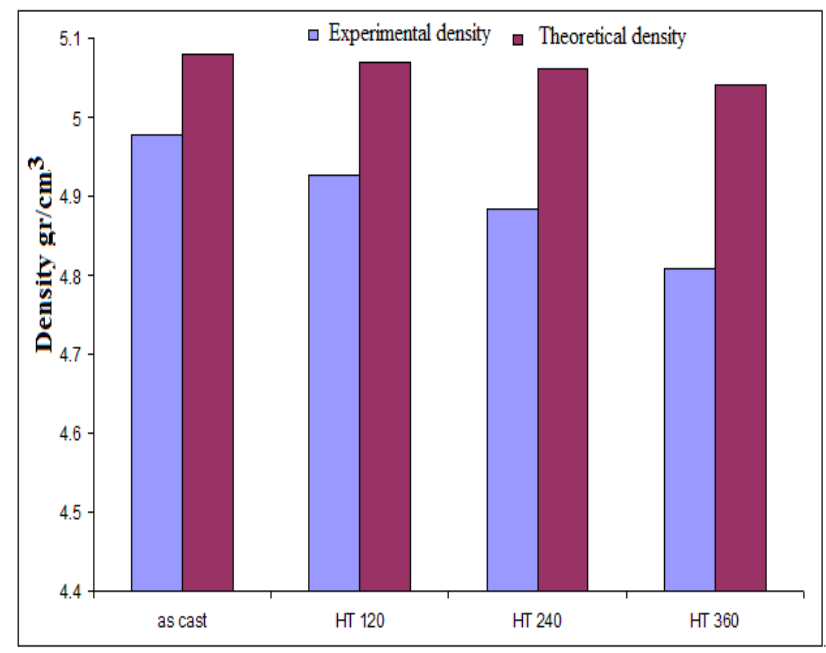

Figure 6: Densities of ZA-27 as cast and heat treatment.

\subsection{Micro Hardness}

Vickers micro hardness (MHV) at positions was recorded for ZA-27, As-cast and heat treatment samples. The results show that the values of micro hardness decreased from cast to treatment and decrease with increase heat treatment as shown in Figure 7, due to grains became bigger and alloy became softer by rising temperature

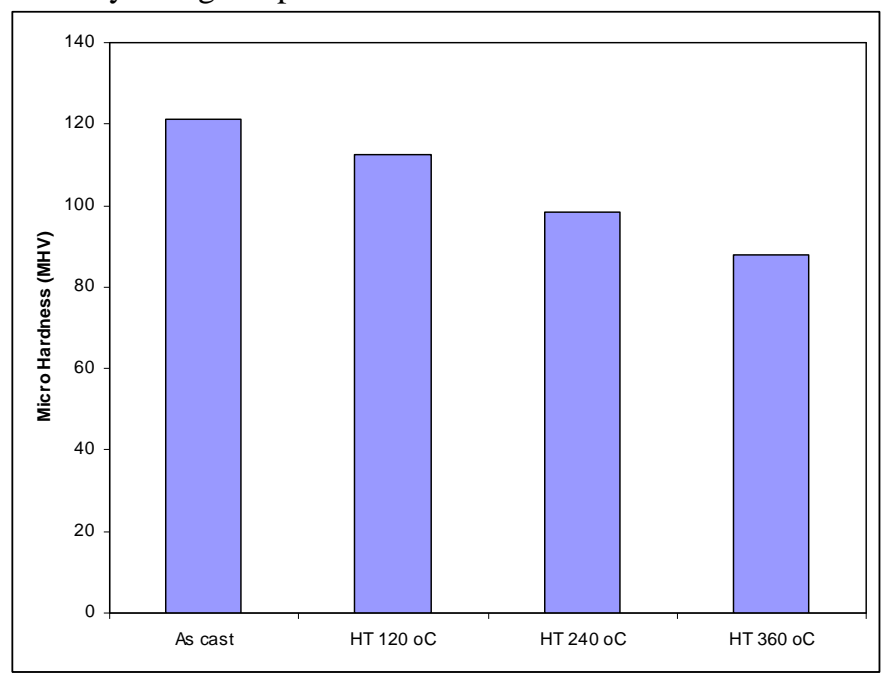

Figure 7: Vickers micro hardness of ZA-27 as cast and heat treatment

\subsection{Tensile strength and elongation investigation}

The tensile strengths test results of ZA-27 as cast and heat treatment shown in Figure 8. It is seen that in all the samples, its decreases with increase of heat treatment temperature from 424 to $323 \mathrm{MPa}$., the elongations results of ZA-27 as cast and heat treatment were as cast $1.8 \%$ and heat treatment at $120{ }^{\circ} \mathrm{C}$ was $2 \%, 240{ }^{\circ} \mathrm{C}$ was $3 \%, 360{ }^{\circ} \mathrm{C}$ was $6 \%$ 


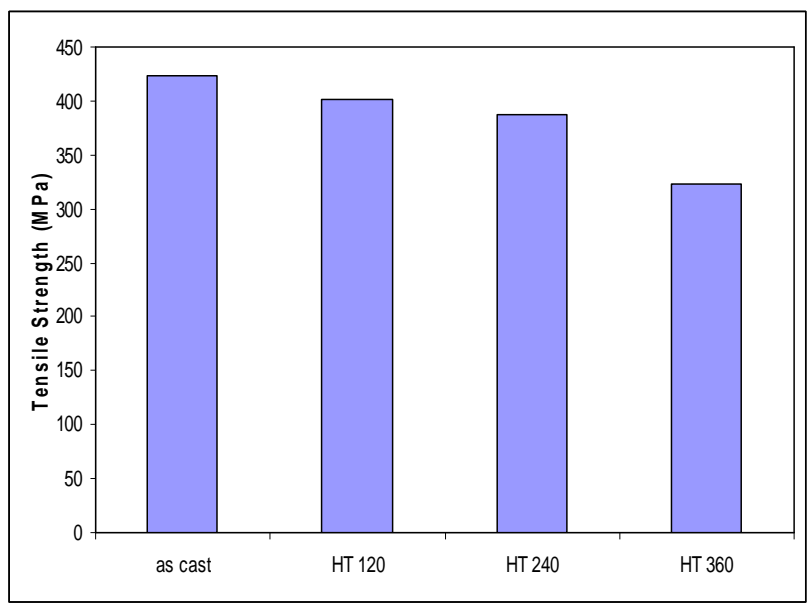

Figure 8: Tensile strength of ZA-27 as cast and heat treatment

\subsection{Compression strength}

To compare between compression strength of of ZA-27 as cast and heat treatment $\left(120,240\right.$ and $\left.360^{\circ} \mathrm{C}\right)$, compression tests were performed at room temperature. The results of compression test are showed in the figure 9, the results indicate compressive strength decreases with increase of heat treatment temperature from 538.7 to $440.8 \mathrm{MPa}$. Because of rising temperature increase of alloy softer, ZA27 as cast $<$ HT $120<$ HT $240<$ HT $360{ }^{\circ} \mathrm{C}$

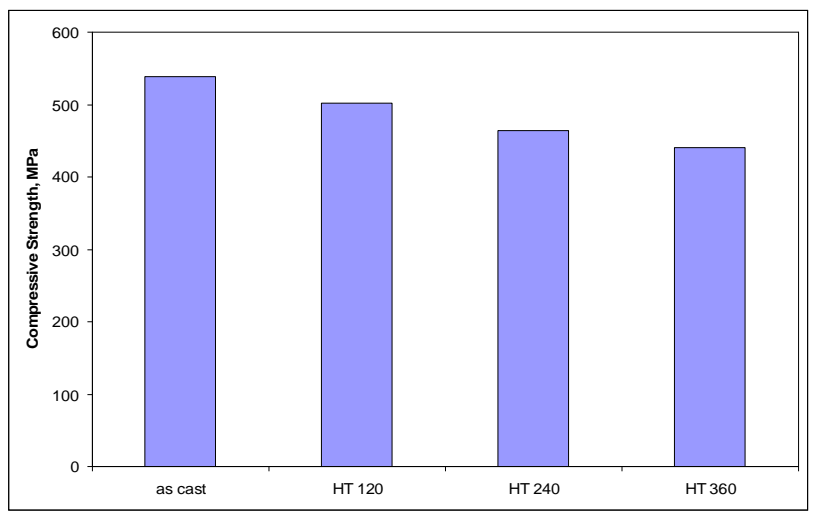

Figure 9: Compression strength of ZA-27 as cast and heat treatment

\subsection{Impact strength}

Figure 10, shows impact strength of Z A-27 as-cast and treatments in terms of impact energy absorbed during Charpy impact test. The results showed increased in impact strength with increased heat treatment temperature from 40 Joule as-cast to 56 Joule at $360{ }^{\circ} \mathrm{C}$ at same velocity.

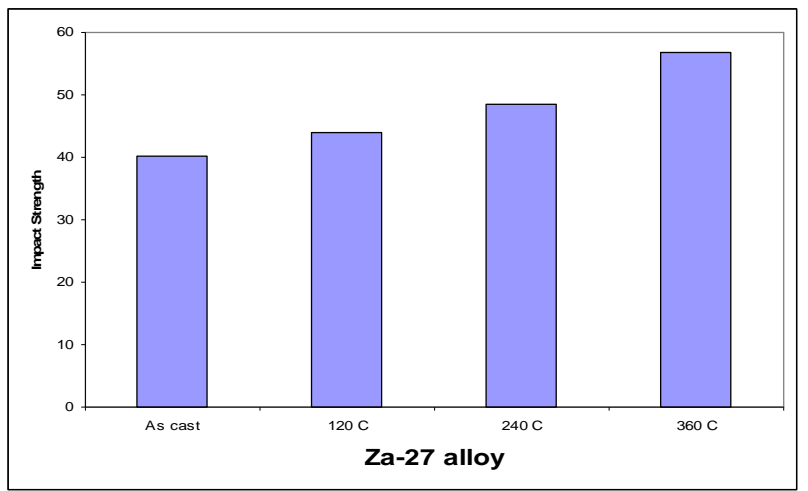

Figure 10: Effect of heat treatment on the impact strength of ZA-27

\subsection{Wear Behavior}

In figure 11, represents the pin weight loss of the different ZA27 alloys as-cast and heat treatment with applied loads at constant sliding speed was $0.65 \mathrm{~m} / \mathrm{s}$. Weight loss increases with increasing the applied load. It is interesting to note that wear loss of the heat-treated alloys is significantly lower as compared to as-cast. We can notice, in all that investigated alloys, intensity of wear rate increased with the increased of the load force. However, indicate of that increase is not the same for all the alloys.

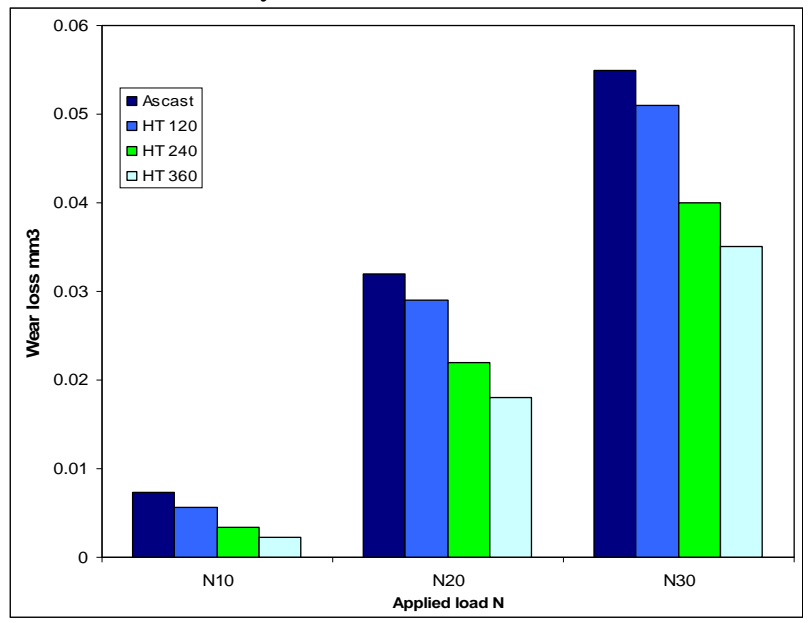

Figure 11: Wear rate vs. applied load for ZA-27 as-cast and heat-treated

In Figures 12 are shown the SEM micrographs of the worn surfaces of the tested alloys, under the following conditions: $\mathrm{v}=0.68 \mathrm{~m} / \mathrm{s}$ and $\mathrm{Fn}=30 \mathrm{~N}$. On all the worn surfaces, can clearly seen the wear scars in the direction of the contact motions, what basically represents the consequence of the micro-abrasive wear of alloys samples with the discs of significantly higher hardness. Besides this wear mechanism, existence of the material transferred to the contact surfaces of discs and the contact surfaces of the alloys (clearly visible in Figure 12) clearly point to presence of the adhesive wear. In addition, on contact surface one can notice the craters of different depths and shapes, which are the consequence of the fatigue wear. Even by the superficial glance at the worn surfaces, one can easily notice the morphological differences that correspond to certain types of alloys, the cast alloy and 
the heat treated alloys correspond relatively smooth surfaces with shallow wear scars. Significantly, rougher worn surfaces correspond to the pressed and the cast alloy. On those surfaces, one can notice the rougher wear scars, for cast alloy and micro deformation and micro destructions traces for heat treatment
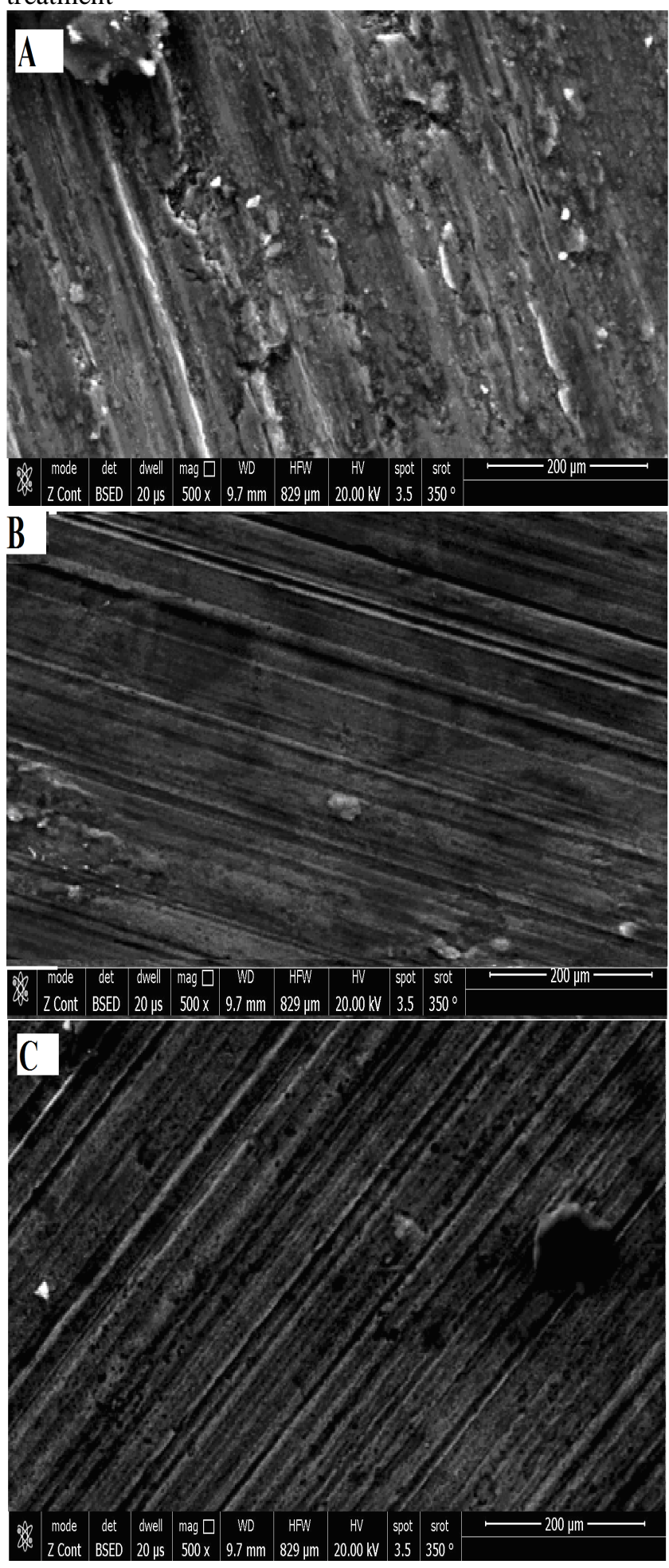

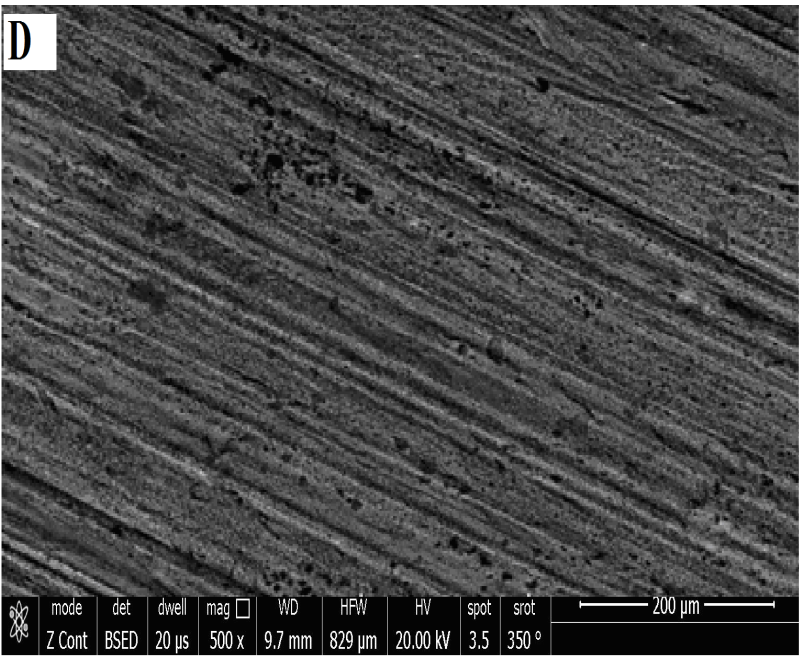

Figure 12: SEM images worn surface of ZA-27 alloy heat treatment for $1 \mathrm{hr}$; A): $0{ }^{\circ} \mathrm{C}, \mathrm{B}$ ): $\left.120^{\circ} \mathrm{C}, \mathrm{C}\right): 240{ }^{\circ} \mathrm{C}$ and D): $360{ }^{\circ} \mathrm{C}$

\section{CONCLUSION}

Produced of ZA-27 alloy and effect of heat treatment on physical and mechanical properties as:

1) The density of ZA-27 as cast higher than heat treatment ZA-27 may be dimensional change in ZA-27 alloy during solid solution treatment and convert of meta-stable phases to stable phase

2) Microstructure of ZA-27 alloy as-cast consists of dendrites of primary $\alpha$ phase, $\beta$ phase around the primary $\alpha$ phase, $\eta$ phase and $\varepsilon$ phase in inter dendrite area.

3) With increase in solid solution temperature, $\alpha$ and $\eta$ phases dissolve into the $\beta$ phases. at solution treatment at $360{ }^{\circ} \mathrm{C}$ for $1 \mathrm{~h}$, the microstructure composed of the supersaturated $\beta$ phase mainly with small Al-rich ( $\alpha$ phases) on grain boundaries.

4) Hardness, tensile strength and compressive strength decrease with increase heat treatment temperature, while plays an important role in improving the tensile elongation and elasticity

5) Heat treatment improved the impact strength by significant amounts. The increases percentage in impact strength of ZA-27 alloy (As-cast, $360^{\circ} \mathrm{C}$ ) was $40 \%$

6) Heat treatment of ZA-27 alloy increase tribological behavior, for all applied loads in dry sliding conditions at constant velocity. ZA-27 as cast less than $\mathrm{HT} 120^{\circ} \mathrm{C}$ less than $\mathrm{HT} 240^{\circ} \mathrm{C}$ less than $\mathrm{HT} 360^{\circ} \mathrm{C}$ in wear rate

7) The rougher wear scars for cast alloy and micro deformation and micro destructions traces for heat treatment

\section{REFERENCES}

[1]: Zhu Y H. General rule of phase decomposition in Zn-Al based alloys (II) - On effects of external stresses on phase transformation, Jour. of Mater Trans, vol. 45, 2004. [2]: Yang Liu, Hong-ying LI, Hao-fan Jiang, Xiao-chao LU, Effects of heat treatment on microstructure and mechanical properties of ZA27 alloy, Trans. Nonferrous Met. Soc. China vol. 23, 2013 
[3]: Zhu Y H, Lee W B, To S. Ageing characteristics of cast Zn-Al based alloy (ZnAl7Cu3), jour of J Mater Sci, 38: 1945-1952., 2003

[4]: M.T. Abou El-khair, A. Daoud, A. Ismail. Effect of different Al contents on the microstructure, tensile and wear properties of Zn-based alloy, journal of Mater. Lett, vol. 58, 2004.

[5]: A Ashuri H. Globular structure of ZA27 alloy by thermo-mechanical and semi-solid treatment, jour. of Mater Sci Eng A, vol. 391, 2005.

[6] K.H.W., Sharma, S.C., Rao, P.R and B. M. Girish, Mechanical properties of as-cast and heat-treated ZA-27/graphite particulate composites, Jour. of Composites Part A, vol. 28, 1997

[7]: Türk A, Durman M, Kayali E S. The effect of manganese on the microstructure and mechanical properties of zinc-aluminum based ZA-8 alloy, jour. of Mater Sci, vol. 42, 2007.

[8]: Wang J H, Huang J F, Su X P, Wu C J. Effect of reverse modification of Al-5Ti-B master alloy on hypoeutectic ZnAl4Y alloy, Jour of Mater Des, 2012, 38: 133-138.

[9]: Annalisa Pola, Marialaura Tocci, Frank E. Goodwin, Review of Microstructures and Properties of Zinc Alloys, Metallurgy Journal, February 2020

[10]: S. C. Sharma, "Tribological Behaviour of Zn-Al-Cu, Journal Bearing with High Load and Low Speed", vol. 1, 2001

[11]: Sava,skan, T.; Hekimo glu, A.P., Microstructure and mechanical properties of $\mathrm{Zn}-15 \mathrm{Al}$-based ternary and quaternary alloys. Jour of Mater. Sci. Eng. A, 603, 52-57, 2014

[12]: Pola, A.; Montesano, L.; Roberti, R. Nuove Leghe di Zinco per L'industria del Design. In Proceedings of the 30th Convegno Nazionale AIM, Brescia, Italy, 10-12 November 2010.

[13]: Temel Savaskan, Ali Pasa Hekimoglu, Gencaga Purcek, effect of copper content on the mechanical and sliding wear properties of monotectoid-based zinc-aluminium-copper alloys, Tribol. Int. 2004,

[14] Run-xia Li, Rong-de Li, Yan-hua Bai, Effect of specific pressure on microstructure and mechanical properties of squeeze casting ZA27 alloy, jour of Transaction of Nonferrous Metals Society of China, 2010, 20: 59-63.

[15]: Abou El-Khair M T, Lotfy A, Daoud A, EL-Sheikh A M. Microstructure, thermal behavior and mechanical properties of squeeze cast $\mathrm{SiC}, \mathrm{ZrO2}$ or $\mathrm{C}$ reinforced ZA27 composites, Jour of Mater Sci Eng A, 2011, 528: 2353-2362.

[16]: Chen T J, Hao Y, Li Y D., Effects of processing parameters on microstructure of thixoformed ZA27 alloy, Jour of Mater Des, 2007, 28: 1279-1287.

[17]: Chen T J, Hao Y, Sun J, Microstructural evolution of previously deformed ZA27 alloy during partial remelting, Jour of Mater Sci Eng A, vol. 337, 2002

[18]: Lehuy H, L'ESPÉRANCE G, Ageing characteristics of dendritic and non-dendritic (stir-cast) $\mathrm{Zn}-\mathrm{Al}$ alloy (ZA-27), Jour. of Mater Sci, vol 26, 1991
[19]: M. Babic, R. Ninkovic, S. Mitrovic, I. Bobic, Influence of Heat Treatment on Tribological Behavior of $\mathrm{Zn}$-Al Alloys, Tribology in industry, Vol 29, No. 1\&2, 2007.

[20]: Bobic, R. Ninkovic, M. Babic, Structural and Mechanical Characteristics of composites With Base Matrix of Rar27 Alloy Reinforced With Al o and Sic Particles, Tribology in industry, Vol. 26, No 1 \& 2, 2004., pp. $21-26$.

[21]: Q.L. Wang, and H.R. Geng, et al., Mater. Sci. Technol. Vol. 29, 10. 2013

[22]: Meng Sheng, Mingyang li, Fang Long Hong Luo, Jinfeng Leng and Haoran Geng, Effects of Melt Thermal-Rate Treatment and Modification of $Y$ on Zn-27Al Alloy, The Minerals, Metals \& Materials Society, JOM, Vol. 67, No. 5, 2015 